\title{
WEBINAR MENGEMAS HASIL PENELITIAN MENJADI ARTIKEL JURNAL ILMIAH UNTUK GURU KIMIA
}

\author{
Sonny Rohimat ${ }^{1}$, Dwi Susilo ${ }^{2}$, Iswarni ${ }^{3}$ \\ ${ }^{1}$ SMA Negeri 6 Kota Serang, Jln. Raya Petir - Serang km. 4 Kota Serang, Banten, Indonesia \\ ${ }^{2}$ SMA Negeri 1 Cileles, Jln. Raya Sampay Gunungkencana KM 25 Cileles Lebak, Banten, Indonesia \\ ${ }^{3}$ SMA Negeri 17 Kabupaten Tangerang, Jln. Raya Perum Legok, Tangerang, Banten, Indonesia \\ Email: albaregbegi@gmail.com
}

\begin{abstract}
Teachers are required to carry out Sustainable Professional Development (PKB) in the form of selfdevelopment activities, scientific publications, and innovative work. To facilitate this, the Banten Province Indonesian Chemistry Educators Association (PPSKI) in collaboration with the Untirta Chemistry Education Department held a webinar with the theme "Packaging Research Results into Scientific Journal Articles." The activity which was held on February 17, 2021 was attended by around 150 participants from various regions in Indonesia through the Zoom Cloud Meetings application and YouTube channel. In his presentation, the speaker explained various things that must be prepared before writing a research article and how to write each component of the article, accompanied by examples. The enthusiasm of the participants can be seen from the high participation of the participants in the polls given by the presenters and the number of participants who submitted questions in the question and answer session. At the end of the event the participants received a free e-certificate which was sent via email filled in the attendance list. This webinar activity is in accordance with the needs of teachers because it is a means of self-development and encourages the implementation of scientific publications. In addition, the use of the Autocrat add-on in distributing e-certificates also received positive responses because participants could get e-certificates very quickly and precisely.
\end{abstract}

Keywords: E-certificate of Webinar; Writing Scientific Articles; Add-ons Autocrat; PPSKI in Banten Province.

\begin{abstract}
ABSTRAK
Guru diwajibkan melakukan Pengembangan Keprofesian Berkelanjutan (PKB) berupa kegiatan pengembangan diri, publikasi ilmiah, dan karya inovatif. Untuk memfasilitasi hal tersebut, Perkumpulan Pendidik Sains Kimia Indonesia (PPSKI) Provinsi Banten bekerja sama dengan Jurusan Pendidikan Kimia Untirta menyelenggarakan acara webinar dengan tema "Mengemas Hasil Penelitian Menjadi Artikel Jurnal Ilmiah.” Kegiatan yang diselenggarakan tanggal 17 Februari 2021 tersebut diikuti oleh sekitar 150 peserta dari berbagai daerah di Indonesia melalui aplikasi Zoom Cloud Meetings dan saluran YouTube. Dalam pemaparannya, pemateri menyampaikan tentang berbagai hal yang harus dipersiapkan sebelum menulis artikel penelitian dan cara penulisan pada setiap komponen artikel yang disertai dengan contoh-contohnya. Antusiasme peserta terlihat dari tingginya partisipasi peserta dalam mengikuti polling yang diberikan oleh pemateri serta banyaknya peserta yang menyampaikan pertanyaan pada sesi tanya jawab. Pada akhir acara peserta memperoleh e-sertifikat gratis yang dikirim melalui email yang diisikan pada daftar hadir. Kegiatan webinar ini sesuai dengan kebutuhan guru karena menjadi salah sarana pengembangan diri serta mendorong pelaksanaan publikasi ilmiah. Selain itu, penggunaan pengaya Autocrat dalam pendistribusian e-sertifikat juga mendapat tanggapan positif karena peserta karena bisa mendapatkan e-sertifikat dengan sangat cepat dan tepat.
\end{abstract}

Kata kunci: E-sertifikat Webinar; Penulisan Artikel Ilmiah; Pengaya Autocrat; PPSKI Provinsi Banten 


\section{PENDAHULUAN}

Berdasarkan Peraturan Menteri Pendayagunaan Aparatur Negara dan Reformasi Birokrasi (Permenpan-RB) Nomor 16 Tahun 2009, guru diwajibkan melaksanakan Pengembangan Keprofesian Berkelanjutan (PKB). Kegiatan PKB tersebut menjadi salah satu syarat untuk pengajuan pengangkatan dan kenaikan pangkat bagi guru PNS. Bahkan pada tahun 2020, portofolio kegiatan PKB menjadi salah satu dokumen yang wajib dimiliki sebagai syarat kelulusan bagi guru yang mengikuti Pendidikan Profesi Guru (PPG). Kegiatan PKB ini terdiri atas pengembangan diri, publikasi ilmiah, dan karya inovatif. Kegiatan pengembangan diri bisa dilakukan melalui diklat fungsional, lokakarya melalui Musyawarah Guru Mata Pelajaran, keikutsertaan pada kegiatan ilmiah (seminar, kologium, atau diskusi panel), atau kegiatan kolektif lainnya yang sesuai dengan tugas dan kewajiban guru. Kegiatan publikasi ilmiah bisa dilakukan melalui presentasi pada forum ilmiah, membuat karya tulis pada bidang pendidikan formal atau pembelajaran, serta membuat buku pelajaran atau pendidikan. Adapun kegiatan karya inovatif bisa dilakukan melalui penemuan teknologi tepat guna, menciptakan karya seni, membuat alat pelajaran, serta menyusun standar/pedoman/soal tingkat nasional atau provinsi.

Dengan adanya wabah Covid-19, pelaksanaan PKB khususnya pengembangan diri, tidak bisa dilaksanakan secara tatap muka. Berbagai kegiatan pengembangan diri untuk guru maupun profesi lainnya lebih banyak dilakukan secara daring (dalam jaringan). Maka pada kondisi tersebut banyak kegiatan pelatihan daring dan webinar. Kegiatan pelatihan daring dan webinar ini sebenarnya memberikan banyak keuntungan kepada para guru sebagai peserta. Para guru bisa mengikuti berbagai kegiatan tanpa harus meninggalkan rumah, bahkan bisa sambil mengerjakan hal-hal yang lain.

Webinar berasal dari dua kata yaitu web dan seminar. Jadi webinar dapat diartikan sebagai seminar, presentasi, pengajaran, atau workshop yang dilakukan secara daring, disampaikan melalui internet, dan dihadiri oleh banyak orang dari lokasi yang berbeda-beda. Dalam kegiatan webinar, peserta dapat berinteraksi melalui video maupun tulisan (Durahman \& Noer, 2019). Dengan demikian kegiatan webinar bisa dimanfaatkan untuk mengembangkan keprofesian oleh berbagai kalangan, termasuk oleh guru. Adapun bukti keikutsertaan dalam kegiatan tersebut bisa berupa surat keterangan atau sertifikat.

Aplikasi yang banyak digunakan untuk penyelenggaraan kegiatan webinar dan pembelajaran jarak jauh lainnya adalah Zoom Cloud Meetings. Aplikasi ini merupakan sebuah media pembelajaran menggunakan video. Platfrom ini gratis dengan batas jumlah peserta dan waktu tertentu dan bisa memiliki kapasitas lebih besar jika menggunakan akun berbayar. Dalam aplikasi Zoom Meeting ini peserta bisa 
berkomunikasi langsung melalui video (Haqien \& Rahman, 2020). Selain itu, pada aplikasi ini peserta juga bisa membagikan berbagai media serta berkomunikasi menggunakan fitur chat. Dengan berbagai kelebihannya, aplikasi Zoom Cloud Meetings saat ini banyak digunakan dalam berbagai kegiatan pertemuan jarak jauh. Pada bidang pendidikan, aplikasi ini sering digunakan untuk proses pembelajaran sehingga guru dan peserta didik bisa berkomunikasi secara langsung walaupun berada pada tempat yang berjauhan. Selain itu, aplikasi ini juga digunakan oleh berbagai kalangan untuk melakukan rapat, seminar, dan pelatihan jarak jauh.

Akan tetapi aplikasi Zoom Cloud Meetings juga memiliki beberapa kendala dalam pelaksanaannya. Peserta seringkali mendapat kesulitan untuk bergabung dalam pertemuan yang menggunakan aplikasi ini. Banyak juga peserta yang sering terlempar dari ruangan pertemuan karena ketidakstabilan jaringan internet. Jumlah peserta pertemuan pada Zoom Cloud Meetings juga dibatasi sesuai dengan paket pembayaran yang digunakan. Selain itu, jika masalah muncul dari penyelenggara maka harus dibuatkan jadwal pertemuan yang baru. Untuk masuk ke jadwal pertemuan yang baru biasanya peserta harus masuk menggunakan tautan yang baru juga. Dengan demikian maka penyelenggara harus menyampaikan kembali tautan pertemuan kepada seluruh peserta.

Untuk mengantisipasi masalah yang mungkin terjadi pada aplikasi Zoom Cloud Meetings, biasanya penyelenggara webinar mengubungkan aplikasi tersebut ke saluran YouTube. Dewasa ini YouTube merupakan jaringan media sosial untuk sharing video online yang paling banyak diminati masyarakat. Setiap harinya situs ini diakses oleh jutaan orang dari berbagai pelosok dunia, bukan hanya untuk hiburan tetapi juga untuk belajar atau mendapatkan informasi (Mujianto, 2019). Para pengguna YouTube dapat mencari, menonton, mengunggah dan mengunduh video secara gratis. Bahkan mereka juga bisa melakukan diskusi/tanya jawab tentang video dan sekaligus berbagi klip video. Saluran YouTube lebih stabil serta kapasitas peserta yang lebih besar dibandingkan dengan Zoom Cloud Meetings. Selain itu, jika ada kendala yang terjadi pada penyelenggara, peserta biasanya masih bisa menggunakan tautan yang sama.

Kegiatan PKB guru juga bisa dilakukan melalui publikasi ilmiah. Di antara kegiatan tersebut adalah membuat karya tulis dalam bidang pendidikan formal atau pembelajaran, baik dalam bentuk buku, laporan penelitian yang diseminarkan, makalah tinjauan ilmiah, dan artikel 
yang diterbitkan dalam jurnal ilmiah. Masing-masing bentuk publikasi ilmiah tersebut memiliki angka kredit tersendiri. Selain itu, ada bentuk publikasi ilmiah yang wajib dilakukan untuk proses kenaikan golongan tertentu, misalnya penulisan artikel pada jurnal ilmiah ber-ISSN untuk kenaikan golongan di atas IV/a (Kemdikbud, 2016).

Sebagai sebuah organisasi profesi guru, Perkumpulan Pendidik Sains Kimia Indonesia (PPSKI) Provinsi Banten memiliki tanggung jawab untuk memfasilitasi guru, khususnya guru kimia, dalam mengembangkan keprofesiannya. Untuk itu, dalam rangka sosialisasi kepengurusan periode 2020-2023, PPSKI Provinsi Banten menyelenggarakan webinar dengan tema "Mengemas Hasil Penelitian Menjadi Artikel Jurnal Ilmiah." Tema ini dipilih dengan tujuan bisa memberikan manfaat sekaligus dalam dua kegiatan PKB guru. Melalui kegiatan ini, guru bisa melaksanakan pengembangan diri melalui webinar sekaligus mempersiapkan kegiatan publikasi ilmiah melalui penulisan artikel pada jurnal ilmiah. Kegiatan ini diselenggarakan berkerja sama dengan Jurusan Pendidikan Kimia Universitas Sultan Ageng Tirtayasa (Untirta) sebagai mitra PPSKI Provinsi Banten. Pemateri webinar juga merupakan dosen Pendidikan Kimia Untirta yang juga sebagai Editorial Board pada Jurnal EduChemia (Untirta) dan Jurnal Tadris Kimiya (UIN SGD Bandung).

\section{METODE}

Kegiatan yang dilakukan adalah Webinar "Mengemas Hasil Penelitian Menjadi Artikel Ilmiah" yang diselenggarakan dalam rangka sosialisasi Perkumpulan Pendidik Sains Kimia Indonesia (PPSKI) Provinsi Banten. Webinar diselenggarakan oleh PPSKI Provinsi Banten bekerja sama dengan Jurusan Pendidikan Kimia Universitas Sultan Ageng Tirtayasa (Untirta) pada tanggal 17 Februari 2021 menggunakan aplikasi Zoom Cloud Meetings dan saluran YouTube. Peserta webinar adalah guru, dosen, dan mahasiswa pendidikan kimia dari berbagai daerah di Indonesia. Jumlah peserta yang hadir sekitar 150 orang. Adapun peserta yang mengisi daftar hadir melalui Google Form adalah 137 orang karena ada sebagian peserta yang terdeteksi di Zoom atau YouTube tetapi tidak mengisi daftar hadir. Peserta mengikuti kegiatan ini secara gratis serta mendapatkan e-sertifikat yang dikirim secara otomatis melalui email masingmasing.

\section{HASIL DAN PEMBAHASAN}

Kegiatan webinar ini diselenggarakan pada tanggal 17 Februari 2021 menggunakan aplikasi Zoom Cloud Meetings dan YouTube. Peserta mendapatkan tautan Zoom Cloud Meetings dan YouTube melalui flyer serta grup What's App PPSKI Provinsi Banten. Aplikasi Zoom Cloud Meetings diutamakan untuk guru-guru kimia yang berasal dari Provinsi Banten. 
Adapun saluran YouTube diperuntukkan bagi peserta yang mengalami kendala mengikuti kegiatan melalui Zoom Cloud Meetings. Peserta yang menghadiri acara webinar ini berasal dari berbagai daerah di Indonesia.

Kegiatan diawali dengan sambutan dari Ketua PPSKI Provinsi Banten, Ketua Jurusan Pendidikan Kimia Untirta, dan Ketua PPSKI Pusat. Ketua PPSKI Provinsi Banten Dwi Susilo, M.Pd. menyampaikan profil kepengurusan PPSKI Provinsi Banten periode 2020-2023 serta kemitraan dengan Jurusan Pendidikan Kimia Untirta. Ketua Jurusan Pendidikan Kimia Untirta Dr. Solfarina, S.Pd., M.Si. menyambut baik kegiatan yang diselenggarakan oleh PPSKI Provinsi Banten dan menyampaikan harapan agar kerja sama tersebut bisa terus berlanjut untuk memajukan pendidikan kimia di Provinsi Banten. Adapun Ketua PPSKI Pusat Drs. H. Jaenudin, M.Si. menyampaikan urgensi penulisan artikel pada jurnal ilmiah, apresiasi atas terjalinnya kerja sama PPSKI Provinsi Banten dengan Jurusan Pendidikan Kimia Untirta, serta profil singkat PPSKI yang awalnya bernama Asosiasi Guru Kimia Indonesia (AGKI).

Kegiatan inti berupa pemaparan materi tentang "Mengemas Hasil Penelitian Menjadi Artikel Ilmiah" disampaikan oleh Robby Zidni, S.Pd., M.Si. dengan dipandu oleh Iswarni, M.Pd. sebagai moderator. Pemateri merupakan dosen Jurusan Pendidikan Kimia Untirta yang juga bertindak sebagai Editorial Board pada Jurnal EduChemia (Untirta) dan Jurnal Tadris Kimiya (UIN Sunan Gunung Djati Bandung). Pemateri juga aktif melakukan publikasi hasil penelitiannya di berbagai jurnal ilmiah. Materi yang disampaikan terdiri dari tiga tahap yaitu Pendahuluan, Persiapan Sebelum Menulis, dan Menulis Artikel Ilmiah.

Pada bagian pendahuluan, pemateri menyampaikan beberapa hal penting terkait materi yang akan dibahas. Sebelum dimulai, pemateri memberikan polling menggunakan aplikasi slido.com berupa pertanyaan tentang karya tulis yang pernah dibuat oleh peserta. Berdasarkan polling ini diketahui bahwa karya tulis yang pernah dibuat oleh peserta webinar adalah skipsi, Penelitian Tindakan Kelas (PTK), dan tesis. Selain itu ada juga beberapa peserta yang pernah membuat karya tulis berupa artikel di jurnal ilmiah, surat kabar, ataupun buku. Pemateri juga menyampaikan tentang karakteristik materi yang disampaikan di webinar serta tentang ragam gaya menulis.

Pada bagian pendahuluan juga pemateri menyampaikan pentingnya menulis artikel ilmiah. Di antara pentingnya menulis artikel ilmiah adalah berkontribusi terhadap ilmu pengetahuan dan untuk memenuhi evaluasi akademik atau jabatan tertentu. Penulisan artikel ilmiah juga banyak digunakan untuk membuat personal research branding, yaitu sebagai bukti yang menunjukkan bahwa seseorang adalah benar-benar peneliti. Selain itu, penulisan artikel ilmiah juga bisa digunakan untuk mengajukan aplikasi pendanaan penelitian.

Pada bagian kedua, pemateri menyampaikan tentang persiapan sebelum menulis artikel 
ilmiah. Beberapa langkah yang dapat dilakukan oleh peserta dalam mempersiapkan penulisan artikel ilmiah adalah sebagai berikut.

1. Mengikuti pelatihan penulisan artikel. Pada kegiatan ini peserta disarankan untuk berdiskusi atau menulis bersama dengan pakar penulisan artikel.

2. Membaca artikel ilmiah bereputasi yang sesuai dengan bidang keilmuan. Pada langkah ini peserta disarankan untuk menulis daftar referensi baik untuk pendahuluan, kajian literatur, ataupun diskusi dan pembahasan. Tempat untuk mencari referensi yang direkomendasikan antara lain Google Scholar atau Google Cendekia, Eric, Science Direct, Web of Science, serta laman jurnal nasional dan internasional. Selain itu, peserta juga disarankan untuk menggunakan software reference list seperti Mendeley, Zotero, atau Endnote.

3. Menetapkan jurnal ilmiah yang dituju. Dalam hal ini jurnal ilmiah dapat diklasifikasikan menjadi jurnal ilmiah nasional, jurnal ilmiah nasional terakreditasi, jurnal ilmiah internasional, dan jurnal ilmiah internasional bereputasi (terindeks scopus atau web of science). Beberapa saran dalam memilih jurnal tujuan adalah memperhatikan peer review, relevansi dengan topik artikel, pilihan model publikasi, tenggat waktu review, isu yang diusung, serta biaya prosesnya.

4. Memperoleh petunjuk penulisan artikel. Pada jurnal online biasanya tersedia panduan penulisan, gaya selingkung, dan juga template artikel. Dalam hal ini penulis harus mengikuti ketentuan penulisan artikel sesuai aturan yang tersedia.

5. Mengecek ulang data penelitian. Pengecekan ini berkaitan dengan analisis data, metode, penyajian, dan lain sebagainya.

6. Menjamin tidak akan ada masalah kepemilikan hak atas artikel ilmiah yang akan diterbitkan. Hal ini berkaitan dengan berbagai pihak yang berkontribusi dalam penelitian yang dilakukan.

Pada bagian ketiga pemateri memaparkan tentang proses pelaksanaan penulisan artikel ilmiah. Pada bagian ini disampaikan perbedaan format antara laporan penelitian, skripsi, tesis dan desertasi (LPSTD) dengan artikel jurnal ilmiah. Secara umum, artikel ilmiah merupakan ringkasan dari LPSTD. Selain itu, pada sebagian jurnal, bagian Hasil digabungkan dengan Pembahasan sebagai Hasil dan Pembahasan.

Pada bagian ini pemateri juga menyampaikan tentang sistematika artikel ilmiah. Sistematika tersebut terdiri atas judul, nama penulis, abstrak, pendahuluan, metode, hasil dan pembahasan, kesimpulan, dan daftar pustaka. Penjelasan dari masing-masing komponen adalah sebagai berikut:

1. Judul harus dapat dengan ringkas mengidentifikasi masalah dan tujuan yang dilaporkan. 
Judul juga harus menarik atau dapat mempengaruhi pembaca untuk membaca seluruh artikel. Jumlah kata pada judul biasanya dibatasi maksimal 12 sampai 15 kata.

2. Nama penulis dicantumkan tanpa gelar akademik disertai nama dan alamat lembaga asal, serta ditempatkan di bawah judul artikel. Penulis juga harus mencantumkan alamat korespondensi atau email. Jumlah penulis bisa lebih dari satu.

3. Abstrak ditulis dalam bahasa Indonesia atau bahasa Inggris dengan panjang sekitar 200 kata (sesuai panduan masing-masing jurnal) yang berisi isu-isu pokok, tujuan penelitian, metode, dan hasil penelitian. Abstrak harus ringkas tetapi menggambarkan keseluruhan ide tentang apa yang telah dilakukan, apa yang telah ditemukan, dan apa kesimpulan utamanya. Pada bagian abawah abstrak dituliskan tiga sampai lima kata kunci.

4. Pendahuluan merupakan informasi tentang latar belakang masalah yang menjadikan penelitian tersebut bersifat penting. Pendahuluan berisi pernyataan singkat tentang masalah, temuan orang lain, tujuan umum penelitian, dan tujuan dari artikel yang dilaporkan.

5. Metode ditulis secara naratif dan detail sehingga tidak ada informasi yang hilang jika orang lain ingin mengulang. Secara umum metode harus menjawab apa, siapa, kapan, di mana, bagaimana, dan mengapa.

6. Hasil dan pembahasan berisi temuan beserta analisisnya. Hasil merupakan ringkasan data penelitian dan bisa dilengkapi dengan tabel, grafik atau foto. Adapun pembahasan merupakan penafsiran terhadap data hasil penelitian. Pada pembahasan, penulis mengaitkan teori dengan pemahaman terkini, menjelaskan logika yang memungkinkan untuk menerima atau menolak hipotesis, serta menjelaskan ugrensi dan keunikan hasil penelitian.

7. Kesimpulan memuat tentang jawaban atas pertanyaan atau tujuan penelitian, menjelaskan perbedaan dan temuan tidak terduga, serta menyatakan pentingnya penemuan dan implikasinya di masa depan.

8. Daftar pustaka ditulis dengan cara merujuk pada gaya selingkung jurnal. Penulis juga disarankan untuk menggunakan software reference list seperti Mendeley atau Zotero.

Pemaparan masing-masing komponen artikel tersebut disertai dengan contoh-contoh dari artikel yang sudah diterbitkan. Pemateri juga menyarankan agar penulis membaca ulang seluruh manuskrip serta meminta bantuan orang lain untuk memberikan masukan. Untuk artikel yang menggunakan bahasa Inggris, penulis disarankan melakukan pengecekan grammar sebelum menyerahkan artikel yang ditulisnya dengan menggunakan aplikasi atau meminta bantuan ahli (native speaker). 
Pemaparan materi ini juga diselingi dengan beberapa polling sehingga webinar menjadi lebih interaktif. Polling berupa pertanyaan untuk mengetahui pendapat peserta terhadap materi yang sedang dibahas. Berikut pertanyaan-pertanyaan yang disampaikan dalam polling tersebut:

1. Apakah Bapak/Ibu mempunyai hasil penelitian (PTK atau non-PTK) yang ingin dipublikasikan di jurnal nasional bereputasi? Jawaban terdiri dari empat pilihan yaitu sudah membuat laporan penelitian dan ingin dipublikasikan, memiliki hasil penelitian tapi belum membuat laporannya, belum penelitian tetapi memiliki ide untuk penelitian, serta belum memiliki ide penelitian.

2. Ketika menulis artikel ilmiah, pada bagian manakah Bapak/Ibu banyak menemui kesulitan? (bisa lebih dari satu jawaban). Jawaban berupa bagian-bagian artikel ilmiah yaitu judul, abstrak, pendahuluan, metode, hasil, pembahasan, dan kesimpulan.

3. Manakah judul artikel ilmiah yang baik? (bisa lebih dari satu jawaban). Jawaban berupa contoh-contoh judul artikel penelitian dalam bahasa Indonesia dan bahasa Inggris.

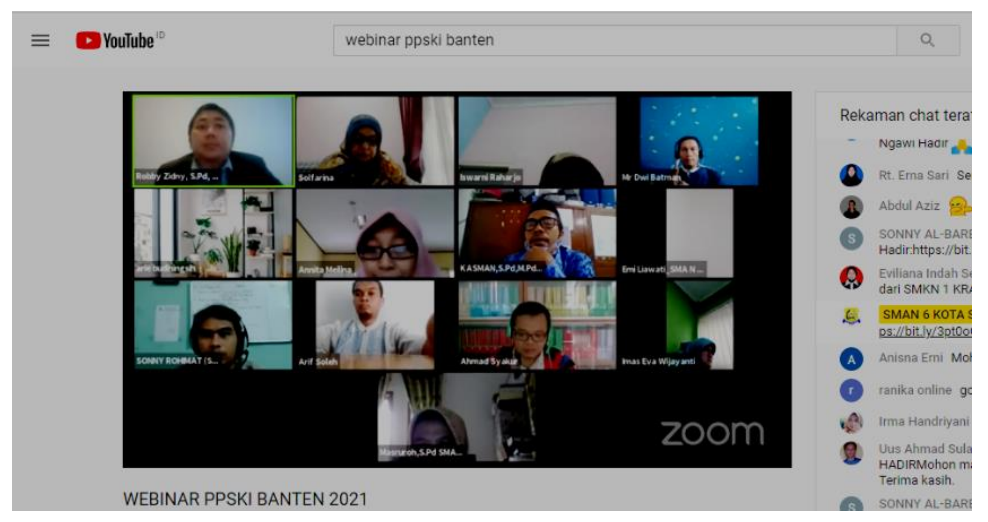

Gambar 1. Pelaksanaan Webinar PPSKI Provinsi Banten

Setelah pemaparan materi selesai, acara dilanjutkan dengan tanya jawab. Pada sesi ini ada banyak pertanyaan dari peserta yang berkaitan dengan penulisan artikel, khususnya penelitian berupa PTK. Tanya jawab meliputi validasi intrumen PTK, pemilihan judul, ruang lingkup publikasi jurnal ilmiah, rentang waktu penelitian dengan publikasi artikel, serta biaya proses publikasi. Pertanyaan-pertanyaan tersebut disampaikan secara lisan oleh peserta yang hadir melalui Zoom Cloud Meetings dan secara tertulis melalui fitur chat Zoom Cloud Meetings ataupun YouTube.

Sebagai bukti keikutsertaan dalam kegiatan webinar ini, setiap peserta mendapatkan esertifikat secara gratis. E-sertifikat yang sudah terisi nama masing-masing peserta dikirimkan melalui alamat e-mail berdasarkan isian daftar hadir. Daftar hadir kegiatan ini disebarkan melalui fitur chat pada aplikasi Zoom Cloud Meetings maupun saluran YouTube kemudian diisi 
oleh peserta selama beralangsungnya acara webinar. Setiap peserta yang sudah submit pengisian daftar hadir langsung mendapat kiriman e-sertifikat secara otomatis. Hal ini disampaikan oleh pembawa acara menjelang penutupan webinar.

Agar proses pendistribusian e-sertifikat peserta webinar secara cepat ini terlaksana dengan baik, penyelenggara merancang pendistribusiannya dengan menggunakan pengaya Autocrat. Pengaya Autocrat ini dipasang dan diatur pada Google Sheets yang berisi respon atau isian daftar hadir peserta webinar. Adapun desain e-sertifikat yang digunakan adalah e-sertifikat kosong yang diunduh dari internet serta disunting pada beberapa bagian menggunakan aplikasi Paint.Net. Proses pengisian konten sertifikat menggunakan aplikasi Microsoft Publisher 2010 dan disimpan menggunakan format foto (JPG).

Pendistribusian e-sertifikat peserta webinar yang terkirim sangat cepat dan akurat mendapat tanggapan positif dari peserta. Sebagian peserta menyampaikan ucapan terima kasih dan apresiasi karena sudah menerima e-sertifikat tanpa harus menunggu lama. Selain itu, nama yang tertulis di e-sertifikat pun sesuai dengan apa yang dituliskan oleh mereka pada daftar hadir. Tanggapan peserta ini disampaikan melalui fitur chat Zoom Cloud Meetings, saluran YouTube, grup What's App PPSKI Provinsi Banten, dan balasan melalui email pengelola.

Walaupun demikian, ada beberapa peserta yang menyampaikan bahwa e-sertifikatnya belum diterima. Setelah ditelusuri ada beberapa hal yang menyebabkan e-sertifikat tidak terkirim kepada peserta. Pertama, nama peserta tidak ada di daftar hadir. Hal ini dikarenakan pengisian daftar hadir peserta tidak terkirim, kemungkinan besar karena faktor jaringan internet di lokasi peserta mengalami gangguan. Kedua, email peserta tidak valid. Hal ini dikarenakan penulisan alamat email di daftar hadir tidak tepat. Ketiga, e-sertifikat terkirim tidak tepat waktu. Hal ini dikarenakan adanya masalah jaringan internet di lokasi peserta.

Masalah yang muncul segera diatasi dengan cepat oleh pengelola. Peserta yang namanya tidak ada di Google Sheets daftar hadir diminta untuk mengisi kembali daftar hadirnya dan langsung memeriksa kotak masuk pada email masing-masing. Peserta yang namanya sudah ada di daftar hadir tetapi e-sertifikatnya belum terkirim, baik karena email tidak valid atau pengirimanya terlambat, maka e-sertifikat langsung dikirimkan melalui aplikasi What's App.

\section{KESIMPULAN}

Kegiatan webinar yang diselenggarakan oleh PPSKI Provinsi Banten dengan tema "Mengemas Hasil Penelitian Menjadi Artikel Jurnal Ilmiah" sesuai dengan kebutuhan para guru, khususnya guru kimia. Hal ini dapat dilihat dari banyaknya jumlah peserta yang hadir baik melalui Zoom Cloud Meetings maupun saluran YouTube serta partisipasi peserta dalam kegiatan polling dan tanya jawab. Keuntungan yang didapatkan peserta dari keikutsertaan dalam 
acara webinar tersebut adalah mendapatkan e-sertifikat dan pengetahuan yang cukup mendalam tentang penulisan artikel ilmiah hasil penelitian. Keikutsertaan dalam acara webinar dan penulisan artikel hasil penelitian juga merupakan tugas yang menjadi sasaran kinerja bagi guru PNS untuk mendapatkan angka kredit kenaikan pangkat.

Selain itu, ketepatan dan kecepatan pendistribusian e-sertifikat untuk peserta webinar merupakan hal penting yang harus diperhatikan. E-sertifikat merupakan hak yang harus didapatkan oleh masing-masing peserta sebagai bukti keikutsertaan dalam kegiatan webinar. Untuk mendukung kecepatan dan ketepatan pendistribusian e-sertifikat bisa menggunakan pengaya Autocrat pada Google Sheets. Hal ini sangat membantu pengelola webinar dalam menyelesaikan tugas atau kewajibannya terhadap peserta. Pengiriman e-sertifikat yang sangat cepat juga menjadikan para peserta merasa puas dan memberikan apresiasi positif terhadap kinerja pengelola webinar. Untuk itu, pemanfaatan pengaya Autocrat bisa digunakan pengelola webinar atau kegiatan lainnya yang menyediakan sertifikat bagi peserta atau panitia.

\section{UCAPAN TERIMA KASIH}

Ucapan terima kasih disampaikan kepada Bapak Dwi Susilo, M.Pd., CIHC, C.Ht beserta pengurus PPSKI Provinsi Banten, Bapak Drs. H. Jaenudin selaku Ketua PPSKI Pusat, Ibu Dr. Solfarina, S.Pd., M.Si. beserta dosen-dosen Jurusan Pendidikan Kimia Untirta, Bapak Robby Zidny, S.Pd., M.Si. selaku pemateri, Bapak Sibghatullah Mujadidi, M.Pd. selaku operator Zoom Cloud Meetings dan YouTube, serta para peserta Webinar Mengemas Hasil Penelitian Menjadi Artikel Jurnal Ilmiah yang diselenggarakan oleh PPSKI Provinsi Banten.

\section{DAFTAR PUSTAKA}

Durahman, N. \& Noer, Z.M. (2019). Aplikasi Seminar Online (Webinar) untuk Pembinaan Wirausaha Baru. Jurnal Manajemen Informatika (JUMIKA), 6(2), 111-120. http://jurnal.stmik-dci.ac.id/index.php/jumika/article/view/427/477

Haqien, D. \& Rahman, A.A. (2020). Pemanfaatan Zoom Meeting untuk Proses Pembelajaran pada Masa Pandemi Covid-19. SAP (Susunan Artikel Pendidikan), 5(1), 51-56. https://journal.lppmunindra.ac.id/index.php/SAP/article/view/6511/3217

Kementerian Pendayagunaan Aparatur Negara dan Reformasi Birokrasi. (2009). Peraturan Menteri Negara Pendayagunaan Aparatur Negara dan Reformasi Birokrasi Nomor 16 Tahun 2009 tentang Jabatan Fungsional Guru dan Angka Kreditnya. Jakarta.

Kementerian Pendidikan dan Kebudayaan. (2016). Pedoman Kegiatan Pengembangan Keprofesian Berkelanjutan Bagi Guru Pembelajar. Jakarta. 
Mujianto, H. (2019). Pemanfaatan YouTube sebagai Media Ajar dalam Meningkatkan Minat dan Motivasi Belajar. Jurnal Komunikasi Hasil Penelitian dan Pemikiran, 5(1), 135-159. https://journal.uniga.ac.id/index.php/JK/article/view/588/566 